\title{
CIENCIA Y RAZÓN EN LA ECONOMÍA POLÍTICA DESDE LA TEORÍA DEL CIERRE CATEGORIAL. LOS CONCEPTOS DE COMPOSIBILIDAD Y ROTACIÓN RECURRENTE.
}

\author{
Santiago Javier Armesilla Conde \\ Universidad Complutense de Madrid
}

http://dx.doi.org/10.5209/rev_NOMA.2016.v47.n1.52403

\begin{abstract}
Resumen.- En este artículo proponemos una definición alternativa para la Economía Política, de disciplina encargada del estudio de la "administración de los recursos escasos" a la de disciplina racional tecnológica con un campo propio encargada del estudio de la composibilidad de factores dentro de ese campo con vistas a la rotación recurrente de dichos factores en las sociedades políticas y las interacciones entre ellas derivadas e influidas por estas composiciones y esa rotación. Para ello, desde el marco teórico de una concepción materialista de la Economía Política, estudiaremos el surgimiento de la Economía Política como disciplina histórica también a nivel antropológico-político, la relación entre técnica, tecnología y Razón económica y la conformación del campo económico y de su racionalidad.
\end{abstract}

Palabras clave.- Razón económica, técnica, ciencia, tecnología, materialismo económico.

Abstract.- In this article we propose an alternative definition for Political Economy, instead of the discipline for the study of the "management of scarce resources", to the rational technological discipline with its own field that studies the composibility of factors within that field with a view to the recurrent rotation of these factors in political societies, and the interactions between them arising, and influenced, by these compositions and this rotation. To do this, from the theoretical framework of a materialistic conception of Political Economy, we will look at the emergence of Political Economy as a historical discipline also anthropological-political level, the relationship between technical, technology and economic reason and shaping the economic field and their rationality.

Keywords.- Economic Reason, technique, science, technology, economic materialism.

\section{Sobre la definición de Economía como "administración de recursos escasos"}

El concepto de Economía Política (o de "ciencia económica") hace referencia a dos palabras griegas, oikonomía y politikós, que significan respectivamente administración de la casa (en griego, oikos es casa y nomos administración) y ordenamiento de la Polis (la ciudad, el Estado prístino de la Grecia clásica) y los asuntos de sus habitantes (Thompson 2006). Desde Jenofonte (Samuelson y Nordhaus 1948, 4), y pasando por la Política de Aristóteles, especialmente los capítulos III -De la adquisición de los bienes- y IV -Consideración práctica sobre la adquisición de los bienes (Aristóteles 2007, 48-56), la línea definitoria de la disciplina económica hasta el presente ha sido, y es, la de una disciplina racional que estudia el contexto determinante de conformación de la misma, al mismo tiempo que forma parte de él. Un contexto determinante, o armadura, donde los sujetos habitantes de una sociedad política tratan de administrar sus recursos haciendo de su sociedad política, de su Estado, su "casa".

Ahora bien, la analogía entre el hogar doméstico y el Estado, desde la actual Academia económica, entiende que la administración de recursos, o bienes, en una sociedad política así como en una casa particular, siempre se realiza sobre "recursos escasos". Así lo afirman, por ejemplo, Gregory Mankiw (2006, 4-16), 
Paul Samuelson y William Nordhaus (1948, 4), Mark Skousen (1993, 16), Benjamin Perles y Charles M. Sullivan $(1973,11)$, entre otros prestigiosos economistas, definición que, en un sentido muy parecido, también recoge el Diccionario de la Real Academia de la Lengua Española (2001), en su acepción tercera, cuando define la economía como "Ciencia que estudia los métodos más eficaces para satisfacer las necesidades humanas materiales, mediante el empleo de bienes escasos". Para autores como Thomson (2006), la definición de Economía Política puede realizarse como sigue:

1) La recta y prudente administración de los recursos escasos de una sociedad, familia o individuo, con la finalidad de satisfacer sus necesidades en lo material. 2) El estudio de la manera o el modo en que las sociedades gestionan sus recursos escasos para satisfacer las necesidades materiales de sus miembros y de la transformación de los recursos naturales en productos y servicios finales que son distribuidos y/o usados por los individuos que conforman la sociedad. Además, la economía explica el cómo los individuos y organizaciones logran sus ingresos y cómo los invierten.

Sin embargo, a nuestro juicio, esta tradicional definición de Economía Política como "administración de los recursos escasos" de una sociedad política, aún cuando da una dimensión técnica y tecnológica, racional, a la administración de la cosa pública en lo que tiene que ver con el campo económico, dista mucho de ser realista a la hora de tener en cuenta tanto la forma en cómo se conformó el campo económico como a la forma en que la disciplina económica se desarrolló, al tiempo que no es acertada a la hora de tener en cuenta la complejidad del presente político y económico de las sociedades políticas desarrolladas. Ahora entraremos a argumentar nuestra postura, pero valga como introducción el decir que los recursos a administrar que el campo económico produce, y de los que dispone, pueden ser tanto "escasos" como "abundantes".

\section{El surgimiento de la Economía Política a partir de las técnicas y las tecnologías}

La premisa de la que partimos, a la hora de desarrollar como entendemos la Razón económica y sus fundamentos, es que las distintas disciplinas del conocimiento humano llamadas ciencias ( $\mathrm{y}$ entran aquí también las llamadas "ciencias sociales" o "humanas", incluida la Economía Política), históricamente han surgido y surgen de técnicas y tecnologías previamente desarrolladas de las que no se derivan de manera forzosa, pero sí de manera necesaria. La idea de ciencia que permite defender esta postura es la propia de la teoría del cierre categorial (TCC), teoría de la ciencia desarrollada por el filósofo español Gustavo Bueno (1992), y será nuestro marco teórico, por lo que trataremos ahora de resumir sus premisas históricas fundamentales (Bueno 1992, 21).

En cada época histórica la idea de ciencia ha sido distinta. A partir del desarrollo histórico-efectivo de cada disciplina científica, inequívocamente 
moderno y contemporáne ${ }^{1}$, los campos o armaduras de cada ciencia han ido tomando cuerpo diferenciándose unos de otros. En sentido moderno, la idea de ciencia designaría cada elemento conformante de cada uno de dichos campos. No obstante, el sentido histórico de la producción de las ciencias rechazará cualquier alusión al nacimiento de las disciplinas científicas a partir de la filosofía o de la reflexión previa, sin dejar de tener en cuenta las relaciones dialécticas entre observación, construcción científica y filosofía. Por ello, afirmamos que toda definición de ciencia ha de partir de las ciencias categoriales ya conformadas.

El enfoque de la TCC se diferencia de otras concepciones filosóficas de las ciencias en que, en vez de ser epistemológica, basada en la relación sujetoobjeto en la conformación del conocimiento científico, es gnoseológica, lo que significa que más allá de ser una mera "teoría del conocimiento", la TCC absorbe la relación epistemológica sujeto-objeto pero rebasando su fundamento dual y psicológico al tiempo que se opone a ella o a otras de carácter meramente histórico (historicista) o lógico-formal. La TCC defiende una tesis gnoseológica sobre la idea de ciencia en sentido moderno y contemporáneo indisociable de la idea de conformación histórica de las distintas disciplinas científicas en los últimos 500 años, en la cual además del sujeto y el objeto se da una relación trimembre entre la materia que fundamenta la conformación de un campo científico determinado, la forma que adopta esa materia en dicho campo, merced a operaciones regladas de sujetos en cada campo (en dialéctica entre sí) y la verdad resultante de esas operaciones conformadoras que resultan ser las verdades científicas o identidades sintéticas, fundamento o nudo que entrelaza los hilos que tejen cada campo científico (Bueno, 1992). Como todo ello se relaciona con el origen técnico de los campos científicos Gustavo Bueno lo resume así:

La teoría del cierre categorial supone que las ciencias categoriales no proceden de la Filosofía, sino de las tecnología (categoriales), a la vez que dan lugar al desarrollo de las nuevas tecnologías ("la Revolución científica y técnica"). La ciencia geométrica procede de las tecnologías de agrimensores o de albañiles; la ciencia química procede de las tecnologías de metalúrgicos o de tintoreros; la ciencia lingüística procede de las tecnologías de los escribas o de los traductores. Acaso podría decirse que la Filosofía de nuestra tradición (helénica), a diferencia de las filosofías de tradiciones distintas (India, China), está en gran parte moldeada por la Geometría, por cuanto quiere ser una "Geometría de las ideas" (de las ideas que cruzan las categoría y se abren camino a través de ellas). Que los "primeros filósofos" (Tales, Pitágoras, Anaxágoras, Platón...) fueran grandes geómetras no tiene que significar tanto que la Geometría brote de la Filosofía sino más bien lo recíproco. Y propiamente yo diría que no brota ninguna de la otra. La filosofía y las ciencias

\footnotetext{
${ }^{1}$ La Geometría, una de las primeras ciencias categoriales, no se construyó en la Edad Moderna en sentido histórico, siendo a nuestro juicio la gran excepción a esta regla, existiendo por tanto a la definición genérica de ciencia que presentamos, e incluso a la definición misma de Geometría. Aún así, aplicar la idea de ciencia en sentido moderno a la Antigüedad resulta, para nosotros, anacrónico. Puede hablarse, no obstante, de células gnoseológicas (Bueno, 1992: 25), conformándose en diversos campos de la Antigüedad que, por ejemplo en el caso de la Física o de la Astronomía geométrica, pueden rastrearse en Eratóstenes o Arquímedes.
} 
tienen fuentes distintas, pero son fuertes llamadas a confluir (a veces turbulentamente) y al confluir se modifican mutuamente. ${ }^{2}$

Al constituirse la Física gracias a Newton, en gran medida mediante el legado de la Geometría euclidiana aplicada a entidades espacio-temporales, fue posible definir la moderna idea de ciencia y a preguntarse por la naturaleza de las disciplinas científicas. A partir de Newton pudieron constituirse campos gnoseológicos irreductibles a la Mecánica clásica que él inició, como las Geometrías no euclidianas, la Termodinámica o la Química. En sentido dialéctico, las técnicas y tecnologías permiten la conformación de las ciencias, y estas a su vez permiten la conformación de nuevas tecnologías y a nuevas ciencias. Con ello no queremos sino significar el sentido objetivo, concreto e histórico (no eterno) de cristalización, relativamente reciente, de la idea de ciencia.

Definir las ciencias como construcciones históricas implica verlas como instituciones culturales conformadas en sentido suprasubjetivo y con componentes heterogéneos. Las ciencias destacan por su pluralidad, siendo cada una "limitada" por otras ciencias y otras disciplinas del conocimiento (saberes racionales no científicos) ${ }^{3}$. El materialismo filosófico de Gustavo Bueno, que puede ampliarse en sentido específico, también como un materialismo óntico-ontológico, científico (gnoseológico, por su TCC), antropológico, histórico, económico y político, define las ciencias como construcciones históricas institucionales, como instituciones antropológicas o como conjuntos complejos de instituciones históricas, al igual que cada uno de sus componentes materiales y personales (Bueno 2005, 3-52) ${ }^{4}$. Los mismos científicos en cada campo correspondiente serían también instituciones, también llamados sujetos operatorios o gnoseológicos por Bueno (1992), así como sus obras o los sujetos que les ayudan a preparar experimentos, así como los experimentos mismos. Estamos hablando de instituciones antropológicas propias de cada campo categorial cerrado, pero no estanco, de cada disciplina científica ${ }^{5}$.

Las instituciones científicas, al ser suprasubjetivas, actúan y se desarrollan por encima de las voluntades de los sujetos individuales, aún cuando el conocimiento científico lo es siempre respecto de dichos sujetos individuales, pues estos sujetos son los que razonan, recuerdan y conocen, oyen y ven, los conocimientos científicos. Algo que no podría hacer el sujeto social en tanto

\footnotetext{
2 (Bueno 2011, 2).

3 Estos saberes racionales no científicos pueden constituirse como fuentes protocientíficas desde las que organizar cada una de las ciencias, aunque a veces puedan bloquear su construcción. Estos saberes protocientíficos, junto con las ciencias, sirve de límite para reconocer la finitud necesaria del campo gnoseológico de cada ciencia categorial. Entre ellas, a veces se dan incompatibilidades que impiden el conocimiento de una determinada zona de la realidad, mientras que otras veces resultan ser una indispensable ayuda para poder constituir un determinado campo del conocimiento humano.

${ }^{4}$ Una balanza, un telescopio, una probeta, serían también instituciones. Del mismo modo existirían instituciones fuera de cada campo científico, como una composición musical o una obra arquitectónica, incluyendo como instituciones cada uno de los elementos o partes formales de cada uno de estos ejemplos (instrumentos musicales, partituras, ventanas, columnas, etc.).

${ }^{5}$ Así como son instituciones propias de la Arquitectura los obreros, arquitectos o inquilinos que habitan un edificio.
} 
que este, como las ciencias y sus campos, son también suprasubjetivos ${ }^{6}$. Las ciencias, como todo conjunto complejo de instituciones o como toda institución en terminología materialista, son configuraciones producto de la producción (construcción, ensamblaje) de múltiples y plurales componentes por medio del trabajo de sujetos que operan en el campo propio de cada ciencia, partiendo de una materia dada como dijimos más arriba y con la ayuda de determinadas técnicas y tecnologías. Esta idea de producción, de ensamblaje constructivo, permite ver la relación dialéctica entre técnicas, ciencias y tecnologías mediante el trabajo humano organizado y racionalizado institucionalmente. Por medio de las tecnologías y desde sus prácticas precedentes en las que se desenvuelven, las ciencias delimitan sus campos categoriales propios ${ }^{7}$. El materialismo científico entenderá, en resumen, que las ciencias provienen de técnicas y tecnologías previas dando lugar, a su vez, a nuevas tecnologías y nuevas ciencias, desarrollándose y conformándose en un terreno que podríamos denominar "metatecnológico", esencial-ideal, propio.

Por ello, las ideas de ensamblaje y construcción (producción) aplicadas al análisis de la conformación de las ciencias recuperarían términos para el campo del análisis histórico del surgimiento de las ciencias como predecir o explicar, características pensadas hacia el futuro que necesariamente habrá que retrotraer al pasado, en una acción dialéctica conjugada entre la predicción y la retrodicción, las cuales constituirían una unidad que os haría regresar a la idea de producción, de origen económico-político, y que a su vez englobaría las ideas de predicción y retrodicción.

La Economía Política, así como el resto de "ciencias sociales", no es ajena a esta conformación histórica. Sin dejar de afirmar, desde la TCC, que las "ciencias sociales" no son en sí mismas ciencias categoriales como lo son las ciencias formales (Geometría, Álgebra, distintas ramas de las Matemáticas) o las naturales (Física, Química, Termodinámica), pues no tienen aquellos un origen exclusivamente técnico y tecnológico, no obstante, y centrándonos en la Economía Política en particular, la influencia técnica y tecnológica también se da y de manera muy acusada. La Economía Política surgió como disciplina en el siglo XVII, contemporánea a la metafísica de Malebranche, Descartes y Leibniz, produciendose una llamada inversión teológica (Armesilla 2014, 21) de esa misma metafísica o "conversión al Mundo", en virtud de la cual la Teología de la época se transformó tanto en Mecánica clásica como en Economía Política (Bueno 1972, 18).

La progresiva constitución de las ciencias categoriales también ocurre ligada al lenguaje escrito, además del ya mencionado proceso técnico de diferenciación entre clases de especialistas profesionales: ingenieros, artesanos, teólogos, sacerdotes, etc., producido contemporáneamente al proceso moderno de

\footnotetext{
${ }^{6}$ Extracientíficamente, esto tampoco ocurre, pues una obra musical no es solo el conjunto de emociones que siente el público o los músicos que la escuchan. El tejido sonoro envuelve, de manera estructural, a los que constituyen su realidad desde su misma génesis. Algo similar ocurre con las lenguas, los idiomas, en tanto no pueden reducirse de manera exclusiva al habla o a los términos de su comunicación, a pesar de que únicamente a través del habla se generen dichas lenguas, ya que su estructura desborda los procesos de su génesis. La lengua construye, compone y ensambla, al tiempo que expresa, comunica y relaciona.

7 Sin embargo, ello no permitiría considerar a las ciencias categoriales como meras tecnologías, aún cuando la sofisticación tecnológica sea cada vez mayor, y más si es aplicada a campos categoriales científicos.
} 
división en clases sociales de las distintas sociedades políticas, sin llegar a confundirse con él pero complejizándolo cada vez más en sentido lógicoformal. Este proceso culminó en la Modernidad con el comienzo de la constitución de disciplinas del conocimiento diversas hasta el presente, dando lugar con ello a una pluralidad de ciencias categoriales particulares, relativamente autónomas unas de otras, con relaciones categoriales no reducibles solo a meras diferencias gramaticales en el lenguaje escrito. La pluralidad efectiva de las ciencias fue criterio suficiente para el establecimiento de una clasificación de categorías ontológicas para cada una de las ciencias en particular, incluida la Economía Política (Bueno 1972, 20). Así, las categorías científicas comenzaron a ser el espacio mismo del entendimiento humano, durante y después al mismo proceso de constitución histórico-cultural de las ciencias mismas y sus respectivas categorías. Para Bueno, con la constitución de una nueva categoría científica se da el proceso que él llama "cierre categorial" (Bueno 1972, 20-21), proceso histórico, sociológico y antropológicoinstitucional además de científico-gnoseológico, lógico-formal y lógico-material.

Desde una evidencia técnica, para el materialismo científico todas las ciencias procedes de oficios artesanos diferenciados, al igual que la conformación de las clases sociales antes mencionada sin menoscabar la relaciones profesionales en el marco de las relaciones de producción y respecto de la propiedad de los medios de producción (aunque se trata de una influencia recíproca). Las categorías científicas parten, y se desarrollan, desde una tradición gremial propia ${ }^{8}$. El proceso de cierre de las ciencias se produce cuando se establece un sistema operativo de relaciones que, en su origen, tiene potencia suficiente para poder conducir a nuevos términos dentro de cada campo científico. Durante el curso de ese proceso se producen desconexiones con otros campos, las cuales no son principios de cierre categorial, sino sus resultados ejercidos implícita y explícitamente. Se trataría de un mecanismo dialéctico de constitución e institución de nuevas categorías racionales, siendo la realidad positiva de las cosas la que permite la misma separación de esas cosas.

La Economía Política fue, al principio, desarrollada por filósofos sobre todo, y no solo influyeron en ella, por la llamada inversión teológica también ocurrida sobre la Mecánica clásica, de los mencionados Leibniz, Descartes y Malebranche, sino también debido a la influencia de Quesnay o Petty, por no mencionar a Adam Smith. Esta influencia de la Filosofía sobre la Economía Política fue notable al menos hasta finales del siglo XIX y principios del XX, sin contar con la conformación teórica de la disciplina en plena era mercantilista. Antes, los términos de la Economía Política fueron manejados por filósofos profesionales como Platón, Aristóteles, Santo Tomás de Aquino, Nicolás de Oresme, Luis de Molina, Juan de Mariana, Francisco Suárez, David Hume, el mentado Smith, John Stuart Mill, Karl Marx o William Stanley Jevons (Bueno 1972, 33), entre otros grandes nombres. Los economistas profesionales empezaron a surgir con la sistematización e institucionalización académicoformal de la disciplina que impulsaron economistas como el británico Alfred Marshall, quien establece las bases de la Economía Política contemporánea

\footnotetext{
8 "[...] el proceso de constitución categorial de la ciencia moderna no procede, esencialmente, de un corte epistemológico" (Bueno 1972, 26).
} 
(Marshall 1890-2005), y de su corriente dominante y mayoritaria: la economía neoclásica (Méndez Ibisate 2003).

Al perforar esta "envoltura filosófica" que recubre la Economía Política, encontramos un origen tecnológico-institucional, paralelamente desarrollado a dicha "envoltura", no después, y paralelo también a las interpretaciones que sobre los actos económicos de, y dentro de, las sociedades políticas han hecho muchos filósofos. Schumpeter (1954-2012) entendía que la Economía Política no podía conformarse ni desarrollarse prescindiendo de una viva tradición de banqueros, contables, mercaderes, memorialistas, regentes políticos 0 aficionados a su estudio, los cuales, gradualmente, fueron cerrando el campo económico al menos parcialmente en diversas regiones del mismo (Bueno 1972, 34).

Dicho cierre, no obstante, se produce en un campo cuyos términos llevan por todas partes aderezos que no son sino ideas extraeconómicas. Desde su nacimiento, la actual Razón económica está compuesta de términos inequívocamente propios de la Economía Política, pero también de la Psicología, de la Moral, de la Politología y la Política, de las técnicas, ciencias y tecnologías, etc. Estas adherencias han actuado, en numerosas ocasiones, como mecanismos de bloqueo de la Razón económica en sentido categorial, como ya dijimos más arriba. No obstante, al mismo tiempo, estas adherencias permiten la posibilidad de discernir momentos de corte entre ellas y las categorías propiamente económicas (Bueno 1972, 34).

La Razón económica académica, propia de los economistas, tiene por tanto una conexión estrecha con la Razón económica técnica o "mundana" (Bueno $1972,35)$, es decir, la de los depositarios de dinero en cuentas bancarias, la de los inversores de capital en bolsa, la de los accionistas de una empresa, la de los sujetos que operan con medios de producción para producir mercancías (los trabajadores), etc. Mientras la Razón económica mundana se manifiesta en sus operaciones técnicas dentro del campo económico, la de los economistas lo hace por medio de la estritura de libros o artículos, con un lenguaje cada vez más cerrado en terminología de la TCC; lenguaje que, a su vez, también pertenece al campo económico junto con los otros elementos ya citados. El análisis económico no sería, por tanto, más que el que hacen uso, y conforman, los economistas en conjunción dialéctica con otros sujetos actores de las acciones de la Razón económica mundana. Un lenguaje cerrado parejo al lenguaje de ciencias como la Geometría o la Física. Los economistas también analizan acciones, ceremonias e instituciones propias del campo económico como la moneda, el trueque, el intercambio de bienes y servicios en los mercados, las acciones económico-políticas del Estado, etc.

La realidad económica es una realidad racional, cultural, objetiva, concreta, producida por seres racionales humanos, personas que viven en avanzadas y complejas sociedades políticas. Estas personas se relacionan entre sí, económicamente, de manera racional, organizada, institucionalizada, por medio de tecnologías que ayudan a conformar un lenguaje económico, unos símbolos e instituciones que permiten, a su vez, conformar las metodologías propias que hacen uso de ese mismo lenguaje económico y que las conforman al tiempo. Instituciones propias del campo económico como pueda ser el dinero, variable económica y signo indispensable en todo sistema económico complejo. 
Puede considerarse, desde la TCC, a la Economía Política, en tanto que disciplina académica, como un "metalenguaje". Ello conllevaría que al analizar la relación de la Razón económica en el cierre categorial de la misma, nos encontramos con un lenguaje de "segundo orden" respecto a otros lenguajes y metalenguajes. En un Tratado de Economía Política, por ejemplo, una variable $x$ que designe dinero no es dinero, aunque el dinero sí es una variable económica. Este hipotético Tratado, además, sería también un bien económico susceptible de ser comprado en el mercado, cuya lectura y estudio sería un acto de consumo. Si la Economía Política como disciplina está conectada dialécticamente con la Economía Política mundana, y si desde la Academia económica se tratan de refutar unas teorías económicas a otras junto con el intento de refutación de realidades económicas técnicas y políticas propiamente dichas (sistemas económicos, modos de producción) consideradas mundanas desde la Academia, dichas realidades económicas solo podrían refutarse en realidad mediante otras realidades económicas técnicas y políticas no en tanto teorías, sino como sistemas económicos o modos de producción que superasen a los criticados, incluso absorbiéndolos. Y esto dicho aún cuando las teorías económicas sirvan parcialmente de engranaje ideológico para diversas realidades económicas técnicas y políticas.

Si el cierre categorial de la Razón económica es posible desde la TCC, o bien se da entre un campo de términos meramente lingüísticos (producción, cambio, demanda, oferta, consumo, etc.), o bien se daría como un proceso cuyos términos son los propios sujetos reales o las comunidades de sujetos productores y consumidores del campo económico, así como instituciones cuya circularidad es independiente de esos mismos sujetos y sus acciones (la moneda, los bancos, las fábricas, las herramientas de trabajo, las mercancías), o bien en ambos casos a la vez.

La Economía Política académica tendría, en parte, el papel de una gramática con variables que, en los manuales y libros de la disciplina, tuviesen la función de ser metavariables de variables de la Economía Política mundana real, ya que tanto el economista como el ciudadano de a pie suelen manejar los mismos términos referidos al campo económico. Las grandes obras teóricas de la Economía Política están continuamente intercaladas, en su génesis y efectos, con la práctica real de los sistemas económicos complejos. Los términos del lenguaje económico académico, por tanto, no podrían tener autonomía sintáctica, pues la Economía Política no es ni una ciencia formal ni una ciencia natural, sino una disciplina del conocimiento tanto tecnológica como antropológico-política e histórica, pudiendo definirse como una "ciencia real" (Bueno 1972, 38). Los términos de la Economía Política harían siempre referencia a una realidad económica que en sí misma es ya un lenguaje categorizado producto de la Razón en mayor o menor grado.

\section{Relación de la Economía Política con las técnicas y tecnologías. La Razón económica desde la Teoría del Cierre Categorial. Composibilidad y rotación recurrente}

Desde la TCC, para poder dar una definición de la Razón económica, y de la Economía Política en general de manera rigurosa, es necesaria la determinación estructural del cierre categorial de dicha Razón. Hace falta una 
teoría de la especificidad del campo económico como propio de la Razón económica. A las categorías propias de la Economía Política hay que incorporar las estructuras propias del lenguaje científico, y por ello, cualquier organización conceptual de la Economía Política ha de pertenecer a la dialéctica de la propia categoría económica real, mundana, porque se resuelva en ella como realidad y fenómeno, o porque considera a dicho fenómeno como una apariencia que absorbe y transforma el lenguaje económico. Por tanto, el cierre categorial de la Economía Política, allá donde corresponda, ha de venir combinado específicamente, y siempre, en su propio campo (Armesilla 2014).

El circuito de las relaciones de producción con su retroalimentación es, en rigor, un concepto "extraeconómico", tecnológico y general e incluso biológico (Bueno 1972, 37), aplicable por ejemplo a circuitos de retroalimentación en sociedades de insectos u otros seres vivos. Ello no obsta a que pueda considerarse dicho circuito como suficiente para referirse al campo económico aunque deban pertenecer a dicho campo, y de manera exclusiva, las características propias de la categoricidad racional económica. Pues poner en la producción o en la conducta racional del consumidor la esencia de la categoricidad económica supone, desde la perspectiva del cierre categorial, un error ya que la idea de homo oeconomicus es una idea "extraeconómica", sin negar su importancia en la disciplina o, también, en la Antropología Filosófica. La producción puede realizarse fuera del campo económico si se trata de objetos que no son mercancías. La conducta racional del consumidor puede extenderse a todo tipo de conducta individual inteligente sin ser económica.

Para poder explicar el funcionamiento de la Razón económica desde el materialismo económico resultaría insuficiente la determinación específica de notas diferenciales de la Economía Política, por lo que se hace necesaria una determinación de la comprensión del nexo de unión entre diferentes categorías económicas y de su naturaleza histórica, al tiempo que ha de comprenderse un desarrollo dialéctico e histórico interno de las categorías económicas que contenga componentes tanto "extraeconómicos" como intraeconómicos, dentro del campo económico, como puntos límite de dicho campo. El continuo hacerse de la realidad humana dentro del campo económico en dialéctica con otros campos permite realizar la Razón económica. El homo oeconomicus como idea extraeconómica, esencialista y psicologista (Bueno 1972, 38) ha de poder transformarse en un sujeto realizado en la realidad económica misma, ya que la racionalidad humana no es "previa" a la Razón económica. Las instituciones propias del campo económico son reales, tienen una funcionalidad propia dentro de él ${ }^{9}$.

La constitución moderna y contemporánea de la Razón económica ha de permitir la asunción y reinterpretación retrospectiva de las sociedades humanas desarrolladas previas al nacimiento del campo económico, de la sociedades estudiadas por la Antropología clásica y la Paleoantropología. Entender la naturaleza social y animal de estas sociedades humanas previas al Estado prístino antiguo es esencial desde la Razón económica entendida al modo materialista, porque partiendo de estas sociedades humanas y hasta el

\footnotetext{
${ }^{9}$ El dinero, por ejemplo, no sería una institución realizada gracias a una inteligencia racional previa. El dinero no existe previamente a la esencia del dinero. La racionalidad de la institución antropológico-política dinero consiste en haber sido creada dentro del campo económico.
} 
presente, se ha conformado históricamente la racionalidad económica mediante relaciones entre sujetos dentro de un medio que les servía de fuente energética. En este marco se daban dos tipos de relaciones, según la teoría del espacio antropológico materialista: relaciones individuales y sociales de los sujetos con su medio natural, llamadas "radiales", y relaciones de los sujetos entre sí a través de sí mismos y de instituciones propiamente humanas, llamadas "relaciones circulares", a las que hay que añadir las "relaciones angulares" entre sujetos y animales o seres numinosos, divinos (Bueno 1978). A nuestro juicio (Armesilla 2014), el ciclo producción-distribución-intercambiocambio-consumo de las relaciones de producción puede darse en las relaciones radiales sujetos-naturaleza como conducta racional praxeológica (Mises 1949-2013). Pero al tratar de no quedarnos solo con definiciones extraeconómicas de la Razón económica, es necesario que la categoría económica sea pensada dentro de las relaciones circulares. Por ello, expresiones que definen la Economía Política como disciplina que estudia la "actividad humana orientada a la satisfacción de sus necesidades", la "producción del hombre por el hombre" o la "asignación de recursos escasos", las calificaríamos desde una perspectiva materialista económico-política como "extraeconómicas". Las categorías propiamente económicas, a nuestro juicio, y sin negar las relaciones radiales, tienen que tener componentes circulares. Dinero o intercambio comercial son categorías del campo económico, pues su combinación permite la circulación de bienes, y no hay nada más circularista que dicha circulación.

Para Gustavo Bueno, los principios del cierre del campo económico estarían ya presentes en el Tableu de Quesnay (Bueno 1972, 39), ya que su sentido circular hace presentar en esta obra a los productores, como clase social "fértil", intercambiando bienes con los consumidores, como clase social "estéril". También pueden rastrearse estos principios de cierre del campo económico en El Capital de Marx (1867-1999, 476-487) ${ }^{10}$. Presentar las relaciones circulares como componentes esenciales de la categoría económica no excluye, como ya hemos dicho, las relaciones radiales; las primeras se dan por mediación de las segunda (Marx 1867-1999, 10) ${ }^{11}$. Partiendo de relaciones radiales no se puede alcanzar contenidos específicos de la Economía Política, pero a partir de relaciones circulares sí es posible intercalar relaciones radiales para poder construir productos relativos, mercancías, siendo necesaria la adopción de una perspectiva circular y circularista (Armesilla 2014) de la Razón económica para dar con la fórmula de la naturaleza exclusiva de su cierre categorial.

Esta perspectiva circularista todavía nos coloca ante un horizonte demasiado genérico. Las relaciones circulares se dan entre sujetos, individuales y

\footnotetext{
${ }^{10}$ En el capítulo XXI de El Capital podemos observar este cierre cuando Marx presenta la tabla de la reproducción simple del capital. Conceptos como valor de uso, valor de cambio, valortrabajo y mercancía son conceptos circulares y no radiales.

11 "Como en general en toda ciencia histórica, social, al observar el desarrollo de las categorías económicas hay que tener siempre en cuenta que el sujeto -la moderna sociedad burguesa en este caso- es algo dado tanto en la realidad como en la mente, y que las categorías expresan, por lo tanto, formas de ser, determinaciones de la existencia, a menudo simples aspectos, de esta sociedad determinada, de este sujeto. También en el método teórico [de la Economía Política] es necesario que el sujeto, la sociedad, esté siempre presente en la representación como premisa" (Marx 1857-2008, 22-23).
} 
enclasados, clasificados, según un orden lógico, manteniendo relaciones de intercambio entre sí aunque no solo ${ }^{12}$. Reducir la Economía Política a la mera asignación de recursos escasos mediante el intercambio de mercancías elimina otros momentos de la economía como la producción, la distribución o el consumo. Y si unimos a esto el que los términos propios del campo económico, de manera particular los sujetos gnoseológico-económicos, clases de sujetos y "clases de clases" de sujetos que realizan intercambios entre sí junto a las relaciones establecidas entre ellos, no están completamente definidos a este genérico nivel de circularidad, no quedaría otra que desechar, dándola por hecha, la definición de los sujetos económicos como sujetos de necesidades en tanto que esta, también, es una definición extraeconómica, genérica en sentido biológico inoperante desde el materialismo económico-político.

Desde nuestra perspectiva, las necesidades de los sujetos económicos son históricas, objetivas y concretas, y están por encima de las meras necesidades de subsistencia. Se encuentran mediadas por bienes culturales, incluidos los alimentos elaborados e ingeridos bio-culturalmente, haciendo que los sujetos que consumen estos bienes no puedan ser independientes de esos mismos bienes que producen y consumen. Los sujetos que actúan en e campo económico no son meros sujetos psicológicos ni biológicos, sino históricoculturales racionalmente determinables. La racionalidad no es nada al margen de estas relaciones circulares de los sujetos entre sí a través de cosas que esos mismos sujetos producen, pues definir cualquier racionalidad, también la económica, como propiedad general de todo ser humano otra vez nos pondría delante de una determinación extraeconómica. Las relaciones humanas en el campo económico son relaciones racionales, culturales, de comuniación, metalingüísticas, dadas de un modo específico eonómico. Se trata de relaciones simétricas, transitivas y reflexivas (Rubin 1924-1974, 49) ${ }^{13}$. La racionalidad económica será aquella que permita que se den en el campo económico relaciones entre sujetos en sentido circular, establecidas por medio de mercancías (bienes y servicios) y otras instituciones propias de dicho campo, conformadas a través, y en, dicho campo.

La estructura nutricional de las relaciones entre sujetos a través de las mercancías en el campo económico la representa Gustavo Bueno como sigue (Bueno 1972, 47) ${ }^{14}$ :

\footnotetext{
${ }^{12}$ Ver nota 11.

13 "La Economía Política no es una ciencia de las relaciones entre las cosas, como pensaban los economistas vulgares, ni de las relaciones entre las personas y las cosas, como afirmaba la teoría de la utilidad marginal, sino de las relaciones entre las personas en el proceso de producción" (Rubin 1924-1974, 49).

${ }^{14} \mathrm{La}$ tabla puede encontrarse junto a una extensísima explicación de la misma en Bueno (1972, 47-62).
} 


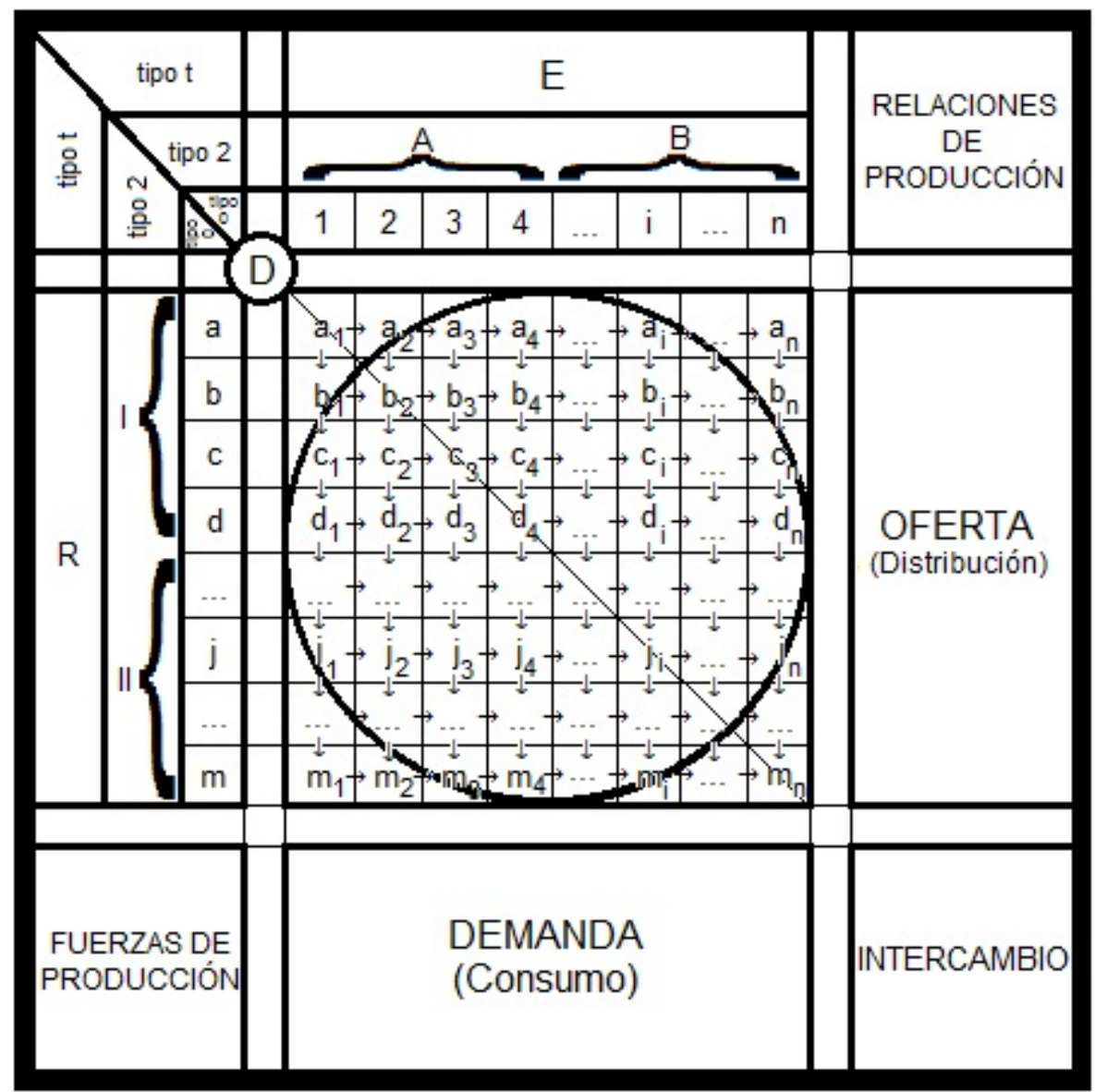

Tabla 1. Tabla de categorías de la Economía Política (Bueno, 1972: 47).

En la tabla puede verse cómo los sujetos dentro del campo económico, representados por los números $1,2,3,4, \ldots, n$, enclasados en las clases sociales o "clases de clases" sociales también de consumidores, productores, $A$, B, etc., dentro del Estado E, se relacionan entre sí circularmente (relaciones de producción) a través de mercancías producidas y consumidas por ellos mismos y representadas por las letras $\mathrm{a}, \mathrm{b}, \mathrm{c}, \mathrm{d}, \ldots, m$, agrupadas a su vez en clases de bienes I, II, etc., clasificación de las mercancías regida objetivamente por el Sistema Armonizado de Designación y Codificación de Mercancías regido y establecido por la Organización Mundial de Aduanas desde la década de 1980 y seguida por cerca de 190 Estados en el Mundo. Este conjunto de mercancías clasificadas representan la riqueza del Estado E, el PIB y el PNB, representada por la letra R, todo ello motor productivo de la sociedad política, las fuerzas de producción. El dinero D sirve como bien, como institución que permite la circularidad de estas relaciones oscilantes entre la oferta y la demanda que dentro del campo económico permite el intercambio de mercancías siempre que éstas puedan, por motivos histórico-sociológicos, puedan hacerse equivalentes a otras mercancías (Bueno 1972, 51). Las fuerzas productivas permiten las relaciones de producción, y al mismo tiempo forman parte de ellas mismas ya que las mercancías que permiten la producción de otras mercancías también son productos históricos cuya existencia influye en el comportamiento de sujetos económicos incluso 
independientemente de la voluntad de estos. Rubin resume el funcionamiento social de la racionalidad económica plasmada en el Gráfico 1 así:

La división social del trabajo une a todos los productores de mercancías en un sistema unificado que recibe el nombre de economía nacional, en un "organismo productivo" cuyas partes se hallan mutuamente relacionadas y condicionadas. ¿Cómo surge esa conexión? Por el intercambio, por el mercado, donde las mercancías de cada productor individual aparecen en forma despersonalizada como ejemplares separados de un tipo determinado de mercancías, independientemente de quién las produjo, o dónde, o en qué condiciones específicas. Las mercancías, los productos de los productores individuales de mercancías, circulan y son evaluadas en el mercado. Las conexiones e interacciones reales entre las empresas individuales -que podríamos llamar independientes y autónomas- surgen de la comparación del valor de los bienes y de su intercambio. En el mercado, la sociedad regula los productos del trabajo, las mercancías, es decir las cosas. De este modo, la comunidad regula indirectamente la actividad laboral de los hombres, ya que la circulación de los bienes en el mercado, el ascenso y caída de sus precios, originan cambios en la distribución de la actividad laboral de los productores de mercancías separados, provoca su entrada en ciertas ramas de la producción, o su salida de ellas, determina la redistribución de las fuerzas productivas de la sociedad (Rubin 1924-1974, 55-56).

Los sistemas económicos no pueden tomarse como algo no material. Tomarlo como algo ideal o metafísico -por ejemplo, la idea de "capitalismo inmaterial" (Cohen 2010)-, equivaldría a nuestro juicio a negar la misma existencia de los sistemas económicos, los cuales se dan dentro de la categoría económica como materialidades atributivas, cuyas variables no pueden aislarse de su campo propio $^{15}$. Si se da algún tipo de reiteración en los sistemas económicos ella ha de permitir la recurrencia del propio sistema económico, esto es, la circularidad de sus relaciones de producción. La reiteración aparece en la perspectiva de la sucesión en el tiempo, trata en conceptos económicos como reproducción simple, ampliada, tiempo de trabajo socialmente necesario, relación entre oferta y demanda, etc.

Los modelos construidos desde la Razón económica académica son analogías casi metafóricas, y aparentemente "externas", respecto de la Razón económica mundana, pues la primera no puede construir modelos "internos" de experimentación como pueden hacerse en las ciencias naturales, ya que en Economía Política no puede realizarse ningún tipo de experimentación constructiva (Bueno 1972, 66) ${ }^{16}$. Ocurre con los propios modelos matemáticos de la Economía Política, que funcionan de manera muy distinta a otros modelos matemáticos de otras ciencias categoriales. Los modelos de la Economía Política suelen ser analogías históricas parciales o modelos abstractos de equilibrio que representan situaciones dadas en el tiempo, sin perjuicio de la

\footnotetext{
${ }^{15}$ Una empresa no puede separarse del resto de empresas de su entorno, ni tampoco puede aislarse la conducta de un grupo de consumidores de la conducta de un grupo de productores. Por ello, cada uno de los elementos del Gráfico 1 no puede reiterarse en su contexto, el cual es simultáneo. Un conjunto de empresas no es una empresa (Ongay 2008, 10), un conjunto de Estados que comercian entre sí no es un Estado (Bueno 2004, 328-341).

${ }_{16}$ Salvo que se trate de aplicaciones de políticas públicas en el marco de la Política Económica, pero aquí se desborda el campo económico de manera más clara.
} 
necesidad de construir modelos matemáticos que tiene la propia Economía Política. Si la Razón económica busca la recurrencia presente y/o futura de un determinado sistema económico, se ha de mover esencialmente ante problemas de composibilidad de factores tanto abundantes como escasos, pues es evidente que se den situaciones de incompatibilidad o inconmensurabilidad que, al poderse producir, bloquearían la propia recurrencia del sistema económico (Bueno 1972, 67). Estas situaciones pertenecen cada vez más a un campo dotado de unicidad material desarrollado históricamente en el curso del tiempo histórico, y más en la actualidad en una situación de globalización de mercados universales donde se dan intercambios continuos de mercancías mediante diversas dialécticas institucionales, empezando por los Estados mismos. Si la composibilidad de factores es el conjunto de acciones económico-políticas para permitir la construcción continua de la racionalidad del campo económico y su rotación recurrente, y la rotación recurrente es la característica esencial de la composibilidad de factores para garantizar su perseverar en el ser y el tiempo, entonces:

La Razón económica académica no puede aspirar nunca a construir cierres categoriales tan rigurosos como la Física o la Biología; la cientificidad de la Economía Política es muy precaria -no por ello menos urgente- y la Razón económica tiene siempre tanto de "prudencia" como de "ciencia" (Bueno 1972, $67)$.

La Economía Política como ciencia "real", en tanto que en diversos espacios de la disciplina puedan estar categorialmente cerrados, ha de poder distinguirse de la práctica económica, técnica, no mantenida de manera estricta en el cierre categorial, pues la Economía Política no mantiene las referencias "idiográficas" consustanciales a la misma como técnica (Bueno 2006, 2) ${ }^{17}$. Por ejemplo, en Matemáticas los momentos puramente científicos son los de exposición de teoremas, definiciones, etc., mientras que sus momentos idiográficos son los problemas matemáticos. Las ciencias cerradas categorialmente en su totalidad (naturales y formales) no contienen proposiciones idiográficas. Esto no quiere decir que sus contenidos sean siempre universalizados. Para que pueda haber cierre en una disciplina el contenido idiográfico ha de ser incorporado al ámbito categorial que le es propio, descontextualizándolo del aquí y ahora. El cierre categorial de toda ciencia no parte únicamente de la deducción, pues su más fértil procedimiento es la construcción gnoseológica, que en Economía Política se corresponde con el concepto de composibilidad y de rotación recurrente. Esta construcción ha de atenerse a una materialidad categorial estricta en todo momento, y no puede ser ni gratuita ni subjetiva. Se trata de construcciones objetivas que ofrecen materiales para la próxima deducción, permitiendo también incorporar contenidos no idiográficos a la misma.

El particular régimen de funcionamiento de la Economía Política se aplica a contenidos idiográficos, y la determinación de estos contenidos es la forma ordinaria de la Razón económica práctica, mundana, aún en sus fases independientes o anteriores a la construcción científica también de la Economía Política. Ello no constituye estos procedimientos, pero sí permiten su avance.

\footnotetext{
${ }^{17}$ No hay ciencias idiográficas, pero sí verdades idiográficas según la TCC, que tienen como referencia un aquí y ahora del continuo espacio-tiempo considerado como centro de coordenadas anclado en el sujeto individual corpóreo o Ego, principal volumen de los contenidos del saber mundano y práctico (Bueno 1972, 68).
} 
La rotación recurrente aplicada a los mercancías (bienes y servicios) del campo económico permite reexponer la fundamental distinción entre dos sectores insertos en el mismo seno de la producción: el de los medios de producción (Sector I del Gráfico 1) y el de los de consumo (Sector II en el Gráfico 1). Las categorías expuestas en el Gráfico 1 han se han de interrelacionar de tal manera que la rotación recurrente de instituciones propias del campo económico permita la estabilidad y permanencia en el tiempo de dicho campo. Todo lo que no se contemple ahí serán adherencias "extraeconómicas". Si los bienes y de producción y de consumo se consumen físicamente, el esquema de la rotación recurrente permitirá construir la distinción entre ambos tipos de bienes. La producción hace referencia a bienes culturales (los que se desprenden de los sujetos que los producen, no siendo todos objetos de producción para el mercado) desconectados de necesidades previas y de fines supuestos.

Las mercancías, los objetos producidos por el hombre que circulan y se componen en el campo económico, se mantienen dentro de la perspectiva general de la idea de recurrencia por la que definimos la Razón económica. Partiendo de uno o varios medios de producción se pueden producir bienes culturales diversos, pues esos medios de producción también son bienes culturales. Toda mercancía, bien o servicio, es un producto cultural muy refinado. La legalidad interna bien clara del campo económico lo permite, porque la circularidad de las mercancías posibilita que unas permitan producir a otras, las cuales se venden o transfieren a otros sujetos enclasados que las utilizan para producir a su vez otras mercancías, y así de manera continúa hasta los bienes de consumo (Bueno 1972, 78) ${ }^{18}$. Y esto debido no a su escasez, sino porque esas mercancías han de ser producidas para que haya rotación recurrente. En palabras de Marx:

En la fórmula general, el producto $P$ se considera como un objeto material distinto de los elementos del capital productivo, como un objeto que lleva una existencia aparte del proceso de producción, una forma útil distinta de las de los elementos de producción. Y así ocurre siempre, cuando el resultado del proceso de producción es un objeto, incluso cuando una parte del producto vuelve a entrar como elemento en el nuevo proceso de producción. El trigo utilizado como simiente sirve para su propia producción, pero el producto es exclusivamente trigo; presenta, por tanto, una forma distinta de la de los otros elementos empleados: la fuerza de trabajo, los instrumentos, el abono (Marx 1883-1999, 50).

\section{Conclusión. Razón económica y cálculo del coste de producción}

Si para nosotros el núcleo de la racionalidad económica reside en la composibilidad de términos abundantes o escasos que integran el proceso productivo (Mar 1894-1999, 325) ${ }^{19}$, que ha de ser recurrente, la Razón económica incluye la gestión y distribución de lo producido, es decir, su

\footnotetext{
18 "Un bien de producción puede consumirse total o parcialmente al realizarse (distinción entre capital fijo y circulante), pero este consumo debe entenderse en un sentido formalmente físico y no económico" (Bueno 1972, 78).

19 "La verdadera ciencia de la Economía Política comienza allí donde el estudio teórico se desplaza del proceso de circulación al proceso de producción" (Marx 1894-1999, 325).
} 
administración y su producción planificada. Todos los sistemas económicos racionales y complejos que han existido y existen han planificado su producción. Mientras la administración económica ha consistido en la composibilidad de composiciones alternativas de recursos, incompatibles entre sí en el tiempo, en esencia también ha incluido la determinación matemática de la producción como puedan ser, a nivel microeconómico, las metodologías de investigación operativa ${ }^{20}$. Esta Razón económica de la programación de la producción es alternativa y se conjuga con la de la administración, siendo dialéctica, y estando en la base de la Razón económica. La programación de la producción equivale al cálculo econométrico de cuánto dinero se tardaría en la producción de cosas concretas que el sistema económico necesita para su recurrencia y cuánto tiempo se tardaría en ello (el tiempo también es esencial para la recurrencia económica). Teniendo el capital disponible óptimo, los medios tecnológicos a mano y tener claras las vías más adecuadas para llevar a cabo la producción de cualquier cosa, son elementos necesarias para conseguir producir, distribuir, intercambiar, cambiar y consumir una mercancía en el menor tiempo y con el menor coste posible.

Este es el primer paso para que sea posible la rotación recurrente en un sistema económico. Si el trabajo socialmente organizado como relación de producción en el campo económico es el bombeo de sangre de todo sistema económico complejo, el que conforma valores de uso que han de consumir los sujetos enclasados de la sociedad política (consumidores o productores, los cuales han de poder hacerse con, o poder manipular, determinados valores de uso para seguir produciendo otros valores de uso, otro elemento fundamental para entender la composibilidad), así como la programación y el cálculo cuantitativo de la producción es lo que permite administrar, ordenar y evolucionar en el tiempo a dicho bombeo de sangre, el cual no es más que la producción tecnológico-cultural de valores de uso plasmados en las mercancías, que permite a los sujetos económicos-políticos relacionarse entre sí mediante dichas mercancías en el campo económico de manera racional.

El estudio del comienzo tecnológico de la rotación recurrente (Marx 1894-1999, $45)^{21}$, el cálculo del coste de producción y las metodologías tecnológicas que permiten este cálculo suponen la institucionalización del cálculo temporal del trabajo socialmente necesario para que la rotación recurrente se pueda dar. Supone también la programación y administración del trabajo humano dentro del campo categorial de la Economía Política, rompiendo al hacerse con la distinción entre naturaleza y cultura en dicho campo y con la conjugación de relaciones circulares y radiales en el marco de la Economía Política (Bueno 1972, 463-470). La idea de producción dentro del campo económico ha sido analizada por grandes economistas, grandes filósofos y otros, tratando de analizar la Economía Política desde la Filosofía. No obstante, el análisis de la idea de producción económica ha de afectar a la idea de consumo, de demanda y a la propia Economía Política como ciencia "real" y cultural que es. Los procesos económicos son recurrentes merced a la producción económica institucionalizada de mercancías, incluido el dinero que sirve de institución

\footnotetext{
20 "La Razón económica, la administración, incluye esencialmente la opción alternativa que se determina matemáticamente en los métodos de programación lineal" (Bueno 1972, 88).

21 "El proceso de la producción capitalista considerado en conjunto representa la unidad del proceso mismo de producción y del proceso de circulación" (Marx 1894-1999, 45).
} 
esencial para la rotación y entretejimiento institucional en la producción y el consumo. Esto es un reflejo de la recurrencia no solo del sistema económico y de la Razón económica misma, sino también, en sentido ontólógico-filosófico, del ser humano como especie, absorbido e inserto en el proceso general de evolución cósmica de la materia (Armesilla 2014, 32).

Fue Willhem Windelband (1924-1998) quien realizó la distinción clásica entre ciencias nomotéticas, que estudian leyes lógicas y buscan estudiar proceso causales e invariables, y ciencias idiográficas, que estudian sucesos cambiantes. La Economía Política, tomada como disciplina idiográfica, se representa claramente en el Cuadro 1, en tanto que plasma una organización institucional de las categorías de la Economía Política, de manera particular en la fase de la producción, y que nosotros hemos esquematizado por nuestra parte así:

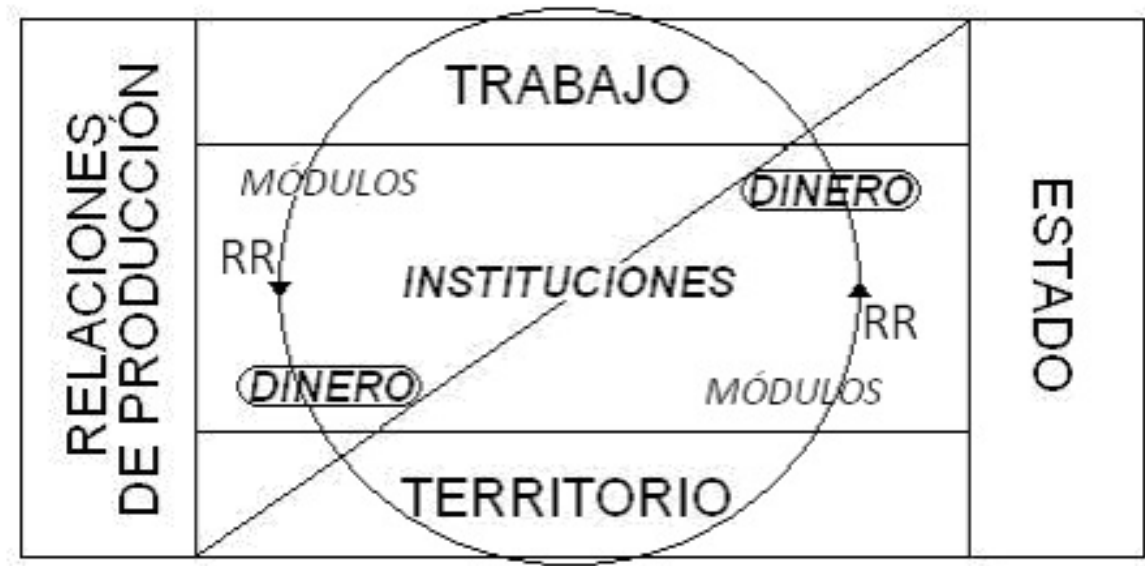

Gráfico 1. Tabla simplificada de las categorías de la Economía Política (Armesilla, 2015: 109).

El cálculo del coste de producción de toda mercancía cuenta con tres elementos fundamentales: la fuerza de trabajo, la materia sobre la que se trabaja y los gastos productivos de fabricación incluyendo los medios de producción. La organización o administración del trabajo esencialmente partirá del gasto de producción inicial, teniendo en cuenta precios de producción varios adicionales al coste de producción como son el coste primario (suma del precio de la fuerza de trabajo y la materia prima de partida), el coste de producción en sí (suma del coste primario y los gastos de fabricación directos e indirectos) y otros gastos como los costes de distribución que afectan a ingresos obtenidos en un tiempo determinado que incluyen gasto de administración, de venta, etc., y los gatos financieros de operación compraventa, llegando así al coste total resultado de sumar costes de producción y distribución previos al proceso comercial producto de la conjunción de oferta y demanda.

El cálculo de los costes de producción y distribución en toda empresa o por parte del Estado se realiza gracias a la contabilidad El gasto total de todo proceso de composibilidad y rotación recurrente de calcula en varios estratos, clasificados alrededor de un objetivo que los permitió empezar y que conformaron su coste, entrando en ese gasto total el coste de materiales 
utilizados, los costes inherentes al proceso productivo que sea y el coste de los salarios a pagar a los sujetos implicados en el proceso que juntos dan lugar al coste de elaboración del producto), los gastos de venta, de administración, los gastos financieros, los conceptos que conforman los costes de distribución de los ingresos por tiempo (meses, trimestres, años, etc.).

Todos estos gastos se han de recuperar por medio de los ingresos conseguidos durante y después del proceso de producción. Se trata de procesos no aleatorios ni espontáneos, que obedecen a una planificación y organización de las relaciones de producción a niveles micro y macroeconómicos tan complejos como los sistemas económicos en que se enmarcan. La organización, el control, la asignación óptima de recursos y operaciones que requieren estos procesos tienen necesidad de una organización técnica, tecnológica y científica muy racional y evolucionada aplicable a cualquier campo, sea propiamente económico o no, pudiendo desarrollarse dentro de la Razón económica ${ }^{22}$. Todo ello, en definitiva, suponen ejemplos de composibilidad de factores sin la cual no es posible la rotación recurrente del campo económico, y viceversa. Ambos conceptos se conjugan para dar lugar lo que hemos presentado aquí como alternativa a la idea dominante de Razón económica académica.

\section{Referencias bibliográficas:}

Aristóteles (s. a. - 2007). Política. Madrid: Austral.

ARMESILLA, S. (2015). Trabajo, utilidad y verdad, Madrid: Maia Ediciones.

Bueno, G. (1972). Ensayo sobre las categorías de la Economía Política. Barcelona: La Gaia Ciencia.

- (1998). Sobre el concepto de espacio antropológico. El Basilisco (1 $1^{a}$ época) 5: pp. 57-96.

- (1992). Teoría del cierre categorial. Oviedo: Pentalfa.

- (2004). La vuelta a la caverna: terrorismo, guerra y globalización. Barcelona: Byblos.

- (2005). Ensayo de una teoría antropológica de las instituciones. El Basilisco (2a época) 37: pp. 3-52.

- (2006). Individual, idiográfico. El Catoblepas 56: p. 2.

\footnotetext{
${ }^{22}$ Así ocurre con la ya mencionada investigación operativa, modelo tecnológico muy avanzado de racionalidad matemática aplicada al campo económico (de composibilidad de factores), que define Martín $(2003,4)$ como la "estructuración de una situación de la vida real como un modelo matemático, logrando una abstracción de los elementos esenciales para que pueda buscarse una solución que concuerde con los objetivos del tomador de decisión [el director de la planificación, nota nuestra]. Esto implica tomar en cuenta el problema dentro del contexto del sistema completo". La investigación operativa tiene su propia metodología de funcionamiento, pero está basada en el desarrollo de procedimientos sistemáticos que permita compara cursos de acción opcionales para escoger el punto más óptimo para llegar a un resultado esperado o bien llevar al valor óptimo de medida del resultado esperado. En lo que respecta al coste de producción, el uso constante de metodologías de investigación operativa para conformarlo es un hecho muy común, y forma por ello parte de las relaciones de producción que permiten la recurrencia de los sistemas económicos complejos que conocemos.
} 
- (2011). Respuesta a la pregunta ¿Qué es el cierre categorial? El Catoblepas 108: p. 2.

COHEN, D. (2010). La prosperidad del mal. Madrid: Taurus.

Diccionario de la Real Academia de la Lengua Española. 2001. Real Academia Española. <http://www.rae.es/recursos/diccionarios/drae>. (Recuperado en 2001).

MankIW, G. (2006). Principios de Economía. Nueva York: McGraw Hill.

Marshall, A. (1890-2005). Principios de Economía Política. Madrid: Síntesis.

MARX, K. (1857-2008). Elementos fundamentales para la crítica de la Economía Política (Grundrisse), Tomo I. Buenos Aires: Siglo XXI.

- (1867-1999). El Capital, Tomo I. México DF: FCE.

- (1883-1999). El Capital, Tomo II. México DF: FCE.

- (1894-1999). El Capital, Tomo III. México DF: FCE.

MÉNDEZ IBISATE, F. (2003). Marginalistas y neoclásicos. Madrid: Síntesis.

MISES, L. (1949-2013). La acción humana. Madrid: Unión Editorial.

ONGAY, I. (2008). Notas en torno al concepto de institución y a las instituciones empresariales. El Catoblepas 79: p. 10.

Perles, B. y Sullivan, C. (1973). Economía para todos. México DF: Compañía Editorial Continental.

RuBin, I. (1924-1974). Ensayos sobre la teoría marxista del valor. Buenos Aires: Pasado y Presente.

Samuelson, P. y Nordhaus, W. (1948). Economía. Nueva York: McGraw Hill.

Schumpeter, J. (1954-2012). Historia del análisis económico. Madrid: Ariel.

Skousen, M. (2006). La Economía en tela de juicio. Madrid: Pearson Educación.

Thomson, I. (2006). Definición de Economía. PromonegocioS.Net. < http://www.promonegocios.net/economia/definicion-economia.html>. (Recuperado en mayo de 2006).

WindeLBAND, W. (1924-1998). History and natural science. Theory and Psichology 8: pp. 6-22. 